\title{
Pre-emptive strike: outwitting extinction
}

\section{A venerable conservation organization predicts how climate change will affect individual species. Will conservationists take pre-emptive action? Emma Marris reports.}

0 ne of the world's largest

conservation organizations, famous for reporting the decline of species over time, has begun to take a more forward-looking approach. The Gland, Switzerland-based International Union for the Conservation of Nature (IUCN) has for 45 years focused on taking snapshots of species at discrete moments in time to assess their conservation status for its Red List of those most in danger of extinction. But with climate change an increasing threat to species worldwide, they are now getting into the business of predicting which will be hardest hit, in order to facilitate what is being dubbed 'pre-emptive conservation'.

The IUCN released the results of its first research efforts to determine which species, and where, are 'climate change susceptible ${ }^{11}$ at its most recent World Conservation Congress in Barcelona, Spain, where over 8,000 delegates gathered from 6 to 14 October. The initial results, which form a chapter of the 2008 Red List review, indicate that that 25 per cent of birds, 28 per cent of amphibians and 51 per cent of corals are not now threatened but could be as temperatures rise. Previous 'climate envelope' models, which look at how the conditions a species lives in will move or disappear as the climate changes, have estimated that 15 to 37 per cent of species may go extinct by 2050 under a mid-range warming scenario ${ }^{1}$.

Wendy Foden, who led the research from an IUCN office in Cambridge, UK, says, "We wanted to see whether or not we are already picking up a lot of those species or whether there was a completely new set of species we need to be focusing on."

\section{TELLTALE TRAITS}

To assess species vulnerability to future warming, 31 volunteer biologists from around the world put their heads

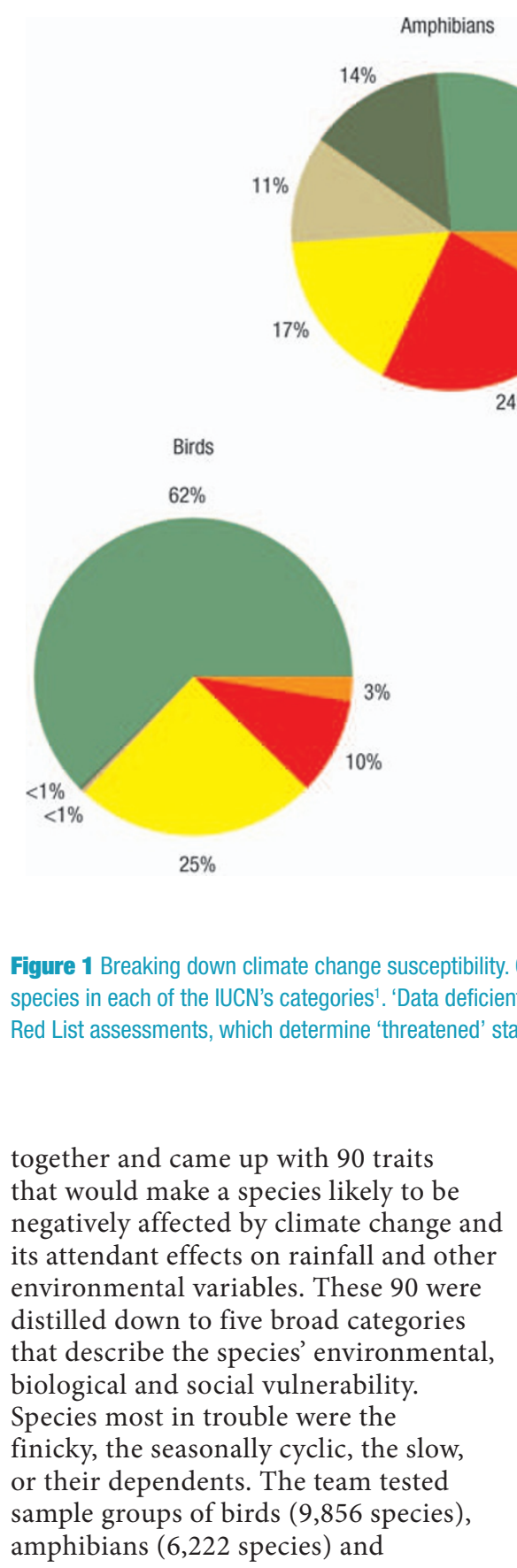

warm-water reef-building corals (799 species) for each of five crucial traits, and categorized the species in each group based on whether they were deemed climate change susceptible and on whether they are currently threatened (Fig. 1).

Of most interest to the IUCN are the non-threatened and susceptible, as these species haven't previously been on their radar. "They are interesting because they probably haven't received much conservation attention or prioritization 
before, and we are saying that they are going to need it," says Foden. These are the species that could be tended to pre-emptively, before they begin to decline.

Perhaps not surprisingly, given their mobility, birds were least likely to be susceptible to climate change: just 10 per cent are currently threatened and susceptible, and 25 per cent are not threatened but are susceptible. Among the birds most likely to be hit hard by climate change are seabirds - albatrosses, penguins, petrels and shearwaters. But birds as diverse as thrushes, ant-birds and sandpipers are also in danger, says the IUCN report.

Reef corals are also likely to suffer, given their sensitivity to water temperature. The IUCN estimates that 19 per cent are currently threatened and susceptible and 51 per cent are climate change susceptible but not threatened, giving a total of 71 per cent of coral species likely to be harmed by warmer waters. Species now categorized as 'least concern' or 'near vulnerable' such as the fat-fingered Acropora gemmifera and the bulbously branching Pocillopora eydouxi may be in danger as the climate continues to change.

The project has produced maps detailing where great numbers of these susceptible species live together. Often the species that are currently threatened and susceptible are not in the same place as those yet to feel the effects of climate change, however. Threatened and susceptible amphibians, for example, are clustered around Central America, where the chytrid fungus is working hand in hand with climate change to clear whole jungles of all amphibian life. In contrast, frogs that are not currently threatened but are most climate change susceptible are centred in Brazil and on the east coast of Africa.

The data released with the 2008 Red List is, Foden says, a mere "halfway point". Ocean acidification, for example, was not factored into the analysis because of unresolved uncertainties. But the finished product, she says, should be useful to "pretty much anyone who uses the Red List". The data may someday be integrated into the Red List itself, so that researchers who map hotspots of threatened species or otherwise model biodiversity can include future climatechange-related threats, even if species appear to be in the pink of health. Parks can be planned, corridors built, and more aggressive measures, such as so-called 'assisted migration', can be

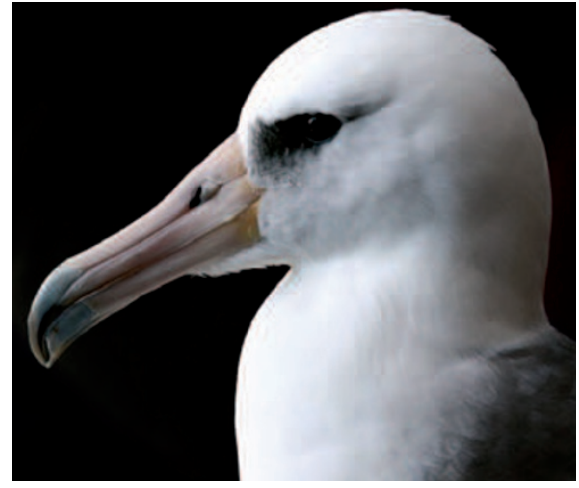

that protected areas have to be much bigger than they were ever thought to be," he says. And although he says climatevulnerability data for species would be "useful", he adds that "the way we are looking at is not at all from a species by species point of view."

Patrick Gonzalez, a climate change scientist at The Nature Conservancy, based in Arlington, Virginia, feels much the same. "We want to make sure that the entire habitat is managed well, and not just a single species," he says. "Even beyond that," he adds, "because of how climate change is shifting vegetation around the world, it raises the question, should we be managing for ecosystem function rather than for particular plants and animals at particular locations?" As an example, he asks which is more important: to have forests of red fir at the top of the Sierra Nevada in California, or that there be some kind of conifer forest with a closed canopy up there?

But more data is always better, he says. "As IUCN data becomes available, I am confident that natural resource management planners will use it as one of many factors that they look at, if it is scientifically credible."

Others disagree that focusing on species is outmoded. "I wouldn't call it old-fashioned," says Cagan H. Sekercioglu, an ecologist at Stanford University in California. "You have to focus on species too. It is really hard to get people excited about ecosystems, in terms of relating to the issue. An organism people can understand and relate to." True. Pandas go a long way. "And a lot of conservation programs, official government programs like the Endangered Species Act, are focused on species," he adds.

In any event, the IUCN will probably want to move with alacrity to get these indicators in place. As Sekercioglu notes, climatic effects on species become visible when they are already taking a toll. "By the time you are seeing a population going down because of climate change, the momentum is too large."

Or, as Foden puts it, "It is not all that pre-emptive. It is already happening."

Published online: 23 October 2008

doi:10.1038/climate.2008.114

Tom Dillon, senior vice president for field programs at the World Wildlife Fund's US headquarters in Washington DC, says that conservation shops are already adjusting their activities to prepare for climate change. Because species will need room to move as their current habitats become unsuitable, "It has become well known

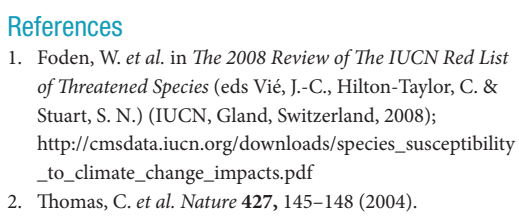

Emma Marris is a correspondent for Nature based in Columbia, Missouri. 